\title{
European Society of Hypertension position paper on renal denervation 2018
}

Citation for published version (APA):

Schmieder, R. E., Mahfoud, F., Azizi, M., Pathak, A., Dimitriadis, K., Kroon, A. A., Ott, C., Scalise, F., Mancia, G., Tsioufis, C., \& ESH Working Group on Interventional Treatment of Hypertension (2018). European Society of Hypertension position paper on renal denervation 2018. Journal of Hypertension, 36(10), 2042-2048. https://doi.org/10.1097/HJH.0000000000001858

Document status and date:

Published: 01/10/2018

DOI:

10.1097/HJH.0000000000001858

Document Version:

Publisher's PDF, also known as Version of record

Document license:

Taverne

Please check the document version of this publication:

- A submitted manuscript is the version of the article upon submission and before peer-review. There can be important differences between the submitted version and the official published version of record.

People interested in the research are advised to contact the author for the final version of the publication, or visit the DOI to the publisher's website.

- The final author version and the galley proof are versions of the publication after peer review.

- The final published version features the final layout of the paper including the volume, issue and page numbers.

Link to publication

\footnotetext{
General rights rights.

- You may freely distribute the URL identifying the publication in the public portal. please follow below link for the End User Agreement:

www.umlib.nl/taverne-license

Take down policy

If you believe that this document breaches copyright please contact us at:

repository@maastrichtuniversity.nl

providing details and we will investigate your claim.
}

Copyright and moral rights for the publications made accessible in the public portal are retained by the authors and/or other copyright owners and it is a condition of accessing publications that users recognise and abide by the legal requirements associated with these

- Users may download and print one copy of any publication from the public portal for the purpose of private study or research.

- You may not further distribute the material or use it for any profit-making activity or commercial gain

If the publication is distributed under the terms of Article $25 \mathrm{fa}$ of the Dutch Copyright Act, indicated by the "Taverne" license above, 


\title{
European Society of Hypertension position paper on renal denervation 2018
}

\author{
Roland E. Schmieder ${ }^{a}$, Felix Mahfoud ${ }^{b}$, Michel Azizi $^{c, d}{ }^{\text {, Atul Pathak }}{ }^{e}$, Kyriakos Dimitriadis ${ }^{f}$, \\ Abraham A. Kroon ${ }^{9}$, Christian Ott ${ }^{a, h}$, Filippo Scalise ${ }^{i}$, Giuseppe Mancia $^{j}$, and Costas Tsioufis ${ }^{k}$, \\ on behalf of Members of the ESH Working Group on Interventional Treatment of Hypertension
}

This ESH update was deemed necessary with the publication of new results of sham-controlled randomized blinded prospective trials with renal denervation (RDN). Proof of concept studies and first randomized trials (some were sham-controlled) displayed discrepant results about the efficacy of RDN. Three sham-controlled randomized trials of the 2.0 generation yielded now similarity in the average blood pressure decrease following RDN. Reduction of ambulatory blood pressure was approximately 5 to 7 $\mathrm{mmHg}$ and of office blood pressure $10 \mathrm{mmHg}$. Such a decrease in blood pressure by pharmacologic therapy has been found to be associated with lower incidence of cardiovascular events in particular with respect to heart failure and stroke by roughly $25 \%$. Nevertheless, some questions about renal denervation are unanswered. The heterogeneity of the blood pressure-lowering response point to the clinical need to identify predictors for efficacy, and questions on long-term safety could not have been answered due to the short duration of the sham-controlled randomized clinical trials.

Keywords: hypertension, renal nerves, renal denervation, randomized controlled trial

\begin{abstract}
Abbreviations: AF, atrial fibrillation; $B P$, blood pressure; CCB, calcium channel blocker; ESC, European Society of Cardiology; ESH, European Society of Hypertension; RCT, randomized controlled trials; FDA, Food and Drug Administration; FU, follow-up; RAS, renin-angiotensinsystem; RDN, renal denervation; US, United States
\end{abstract}

\section{INTRODUCTION}

$\mathrm{E}$ xperts from the European Society of Hypertension (ESH) including the ESH Working Group on interventional treatment of hypertension (HTN) wrote this position paper to update the current status of evidence on endovascular catheter-based renal denervation (RDN) and describe the unmet needs on its application [1]. This update was deemed necessary with the publication of new study results [2-4] that could not be included in the $2018 \mathrm{ESC} / \mathrm{ESH}$ guidelines nor in the US guidelines for the management of arterial HTN prepared ahead [5]. Indeed, three sham-controlled randomized trials (RCT) of second generation (shamcontrolled RCT 2.0) have been published within the last 9 months and will be discussed in detail herein [2].

\section{BAGKGROUND}

Renal nerve activity represents a pivotal neurogenic pathophysiological mechanism of HTN, cardiac and renal disease. Targeting these neurogenic mechanisms has been conducted with surgical, pharmacological and catheterbased interventions, with the goal to decrease the renal efferent sympathetic activity to the kidney and the afferent sensory signals to the central nervous system $[3,4,6]$. The efferent sympathetic signaling to the kidneys are responsible for the elevation of blood pressure (BP) by increasing renal vascular resistance, release of renin from juxtaglomerular cells and increased tubular sodium and water reabsorption $[7,8]$. Conversely, increased afferent signaling from the kidneys triggered by renal ischemia, injury or inflammatory and fibrotic processes lead to an increased sympathetic activity of the central nervous system [8].

Various experimental studies provided evidence that RDN reduces the norepinephrine content in the kidney and, as a consequence, delays or prevents the development of HTN. In humans, catheter-based RDN reduces muscle sympathetic nervous activity (in particular single-unit muscle sympathetic nerve activity reflecting vasoconstrictive fiber nerves) indicating that the sympathetic activity of the central nervous system is decreased after $\operatorname{RDN}[9,10]$. Moreover, renal noradrenaline spillover has been measured in the first 10 patients treated with RDN and a decrease by $47 \%$ was noted [11].

Journal of Hypertension 2018, 36:2042-2048

aUniversity Hospital Erlangen, Department of Nephrology and Hypertension, Erlangen, bepartment of Internal Medicine, Universitätsklinikum des Saarlandes, Saarland University, Homburg/Saar, Germany, ${ }^{C}$ Paris-Descartes University, ${ }^{d}$ Assistance Publique-Hôpitaux de Paris, Hôpital Européen Georges Pompidou, Hypertension Unit, Paris, ${ }^{e}$ Clinique Pasteur, Hypertension, Risk Factors and Heart Failure Unit, Clinical Research Center, Toulouse, France, 'Hippokration General Hospital, Hypertension Unit, Athens, Greece, ${ }^{9}$ Maastricht University Medical Center (Department of Internal Medicine) and Cardiovascular Research Institute Maastricht (CARIM), Maastricht, the Netherlands, ${ }^{h}$ Paracelsus Medical University, Department of Nephrology and Hypertension, Nürnberg, Germany, 'Policlinico di Monza, Interventional Cardiology, Monza, 'University of Milano-Bicocca, Milan, Italy and ${ }^{\mathrm{k}}$ National and Kapodistrian University of Athens, 1st Cardiology Clinic, Hippocratio Hospital, Athens, Greece

Correspondence to Roland E. Schmieder, MD, Head of the Clinical Research Center, Department of Nephrology and Hypertension, University Hospital Erlangen, Ulmenweg 18, 91054 Erlangen, Germany. Tel: +49 913185 36245; fax: +49 913185 36215; e-mail: roland.schmieder@uk-erlangen.de, roland.schmieder@fau.de

Received 13 June 2018 Accepted 14 June 2018

J Hypertens 36:2042-2048 Copyright (C) 2018 Wolters Kluwer Health, Inc. All rights reserved.

DOI:10.1097/HJH.0000000000001858 


\section{PROOF OF GONGEPT STUDIES IN HYPERTENSION}

The first series of proof of concept studies were carried out with various technologies (applying radiofrequency or ultrasound energy or by perivascular injection of neurotoxic substances, such as alcohol) in patients with treatment resistant HTN [12]. The single-arm feasibility and safety study, Symplicity HTN-1, documented an office BP decrease by $15-25 \mathrm{mmHg} 6$ months after unipolar radiofrequency-based RDN with the Symplicity FLEX catheter [13]. Subsequently, data from two randomized but open studies evaluating the same unipolar radiofrequency-based RDN became available. In Symplicity HTN-2, bilateral RDN induced a decrease in office BP by $32 / 12 \mathrm{mmHg}$ and in $24-\mathrm{h}$ ambulatory BP by $11 / 7 \mathrm{mmHg}$ at 6 months [14]. In the Renal Denervation in HTN (DENER-HTN) study, a significant reduction in daytime ambulatory $\mathrm{SBP}$ by $5.9 \mathrm{mmHg}$ in comparison with standard stepped care antihypertensive treatment alone was observed at 6 months [15]. In the DENER-HTN study, the severity of hypertensive disease was less pronounced and baseline BP lower than in the Symplicity HTN-2 study population, thereby explaining the differences in $\mathrm{BP}$ reduction to some extent. Of note, longterm durability of the BP-lowering effect up to 36 months has been found in Symplicity HTN-1 and Symplicity HTN-2 trial [16].

\section{First-generation sham-controlled randomized trials}

The Symplicity HTN-3 study included a larger population $(N=535)$, with ambulatory BP as secondary endpoint, and was sham-controlled, thereby addressing many of the shortcomings of earlier observational or open trials [17]. The study failed to prove any significant reduction in office $\mathrm{BP}$ (primary endpoint) as well as in ambulatory BP 6 months after RDN with the Symplicity catheter compared with the sham procedure in the population of treatment-resistant HTN included in the trial. In the aftermath, several confounders were identified that precluded to find any BPlowering effect of RDN even though the study was shamcontrolled. The most important confounders were uncontrolled changes in the ongoing antihypertensive treatment and nonadherence in the run-in and treatment phase, heterogeneity of included patients, large number of (partially inexperienced) interventionalists (and 34\% of operators carried out only one single procedure), and, most important, the majority of patients $(N=253)$ did not receive a circumferential, four-quadrant renal nerve ablation as required by the protocol [18]. Actually, only 19 out of 340 patients randomized to the RDN intervention had a full four-quadrant ablation at both sides. In face of these confounders, the results of Symplicity HTN-3 with respect to BP efficacy cannot be interpreted reliably. The only clear message that can be taken from this trial is that no safety signal related to the procedure emerged.

Subsequent sham-controlled RCTs included smaller patient cohorts and showed that RDN is at least equally effective to intensive pharmacotherapy in lowering BP in patients with true resistant HTN with less side effects in the
RDN than spironolactone group [19,20]. Two other RCTs, also sham-controlled (single-center studies), revealed a BPlowering effect with RDN, but they also underlined the necessity to carefully monitor technical success during the intervention and uncontrolled drug intake [21,22]. In the second European Clinical Consensus Conference for device-based therapies for HTN, recommendations were made for the next generation of sham-controlled RCTs. The use of new devices and dedicated treatment recommendations are mandated, that is four quadrant ablation at each renal side circumferential. Furthermore, only experienced interventionalists from experienced centers should carry out the procedure, in the absence of any medication, to assess the 'true' BP reduction of RDN. Witnessed intake of medication (if applicable) and/or analysis of medication adherence in each patient should be introduced in the study, and it is recommended that the efficacy is assured by $24-\mathrm{h}$ ambulatory BP monitoring [23].

\section{Second-generation sham-controlled randomized trials}

In the last 9 months, the results of three new RCTs using new radiofrequency or ultrasound based RDN catheters and including different populations of patients have been reported and will be discussed in detail [2].

\section{Study designs}

The Radiance HTN-Solo (ultrasound-based RDN) and the Spyral HTN-OFF MED, and the Spyral HTN-ON MED (radiofrequency-based RDN) trials followed a sham-controlled design. The effectiveness endpoints were the change in daytime ambulatory SBP at 2 months in the RADIANCE HTN-Solo study and the change in 24-h ambulatory BP at 3 months (OFF-MED) and 6 months (ONMED) in the Spyral studies. Patients were to remain off antihypertensive medications throughout follow-up unless prespecified BP criteria were exceeded in the Radiance HTN-SOLO- and SPYRAL-OFF MED trials, whereas in the SPYRAL-HTN ON MED trial, patients were to remain on their baseline medications throughout follow-up unless specified BP criteria were exceeded. The two proof-of-concept Spyral HTN studies reported their results at a third interim analysis when 80 patients were included, and the Radiance HTN-Solo trial randomized a total of 146 patients. Formally, only the Radiance HTNSolo trial was powered to detect a difference of $6 \mathrm{mmHg}$ (SD $12 \mathrm{mmHg}$ ) in daytime ambulatory SBP between the RDN and the sham group. The SPYRAL trials were proofof-concept trials that minimized exposure of patients to an interventional procedure but with the potential to establish sufficient evidence to justify moving to a larger, powered trial thus there were no powered endpoints. All these sham-designed RCT 2.0 followed rigorous recruitment and selection criteria, run-in phase as well as follow-up phase of 2 months (Radiance HTN-Solo), 3 months (SPYRAL HTN-OFF MED) and 3 and 6 months (SPYRAL HTN-ON MED), respectively. In the three trials, both patients and outcome assessors remain blinded to randomization for 6 months at least. In all trials, the followup is extended to 3 years. 


\section{Study population}

In the Radiance HTN-Solo and Spyral HTN-OFF MED trials, all patients were off any antihypertensive medication for 4 weeks before randomization. Inclusion criteria was office $\mathrm{BP}$ at least $140 / 90 \mathrm{mmHg}$ and more than $150 / 90 \mathrm{mmHg}$, respectively, and ambulatory $\mathrm{BP}$ at least $135 / 85 \mathrm{mmHg}$ (daytime) and more than $140 \mathrm{mmHg}$ systolic (24-h average), respectively, after 4-week discontinuation of antihypertensive medications. In addition, patients should have a suitable renal artery anatomy and a low cardiovascular risk profile, and an estimated glomerular filtration rate (eGFR) of more than $40 \mathrm{ml} / \mathrm{min}$ per $1.73 \mathrm{~m}^{2}$ (SOLO) or more than $45 \mathrm{ml} / \mathrm{min}$ per $1.73 \mathrm{~m}^{2}$ (OFF-MED). In contrast, Spyral HTNON MED included patients with the same BP criteria as in Spyral HTN-OFF MED, but concomitant treatment with 1-3 antihypertensive medications was allowed (on average 2.2 medications). Isolated systolic HTN was an exclusion criterion in all three trials. Prior to randomization, baseline BP was lower in Radiance HTN-Solo (office BP 154/ $99 \mathrm{mmHg}$ and 24-h BP 144/88 mmHg) compared with the Spyral HTN-OFF MED (office BP $\sim 162 / 100 \mathrm{mmHg}$ and 24-h BP 152/99 mmHg) and Spyral HTN-ON MED (office BP 164/101 mmHg and 24-h BP 151/97 mmHg), respectively. Thus, driven by request of the FDA and investigator consortiums to analyze the true BP-lowering capacity of RDN in drug-naive patients, we have now two studies available fulfilling these criteria and a third study that analyzed the BP effects on top of $1-3$ antihypertensive medications (the Radiance HTN-TRIO study with three antihypertensive medications is still ongoing).

\section{Procedural details}

The catheter used for renal nerve ablation differed between the trials. The Radiance-HTN trial used a low pressure water-filled cooling balloon catheter that delivers ultrasound energy to thermally ablate the renal sympathetic nerves (Paradise Renal Denervation System; ReCor Medical, Palo Alto, California, USA). It is placed percutaneously within the main renal arteries before the first bifurcation and achieves a circumferential ring of ablation at a depth of $1-6 \mathrm{~mm}$ from the vessel lumen in animal models. The mean total number of ablations was 5.4 in Radiance-HTN Solo. The Spyral multielectrode catheter (Medtronic, Galway, Ireland) is an over-the-wire system that uses radiofrequency-energy and is designed to target the main distal and branch renal arteries. The mean total number of ablations was more than 45 in both Spyral studies.

\section{Findings}

Ambulatory BP: In the Spyral HTN-OFF MED trial, 24-h ambulatory BP was reduced by $5.5 / 4.8 \mathrm{mmHg}$ in the RDN group and $0.5 / 0.4 \mathrm{mmHg}$ in the sham group after 3-month follow-up. The corresponding numbers in the RadianceHTN SOLO trial for daytime ambulatory BP after 2-month follow-up were $8.5 / 5.1 \mathrm{mmHg}$ in the $\mathrm{RDN}$ and 2.2/ $2.6 \mathrm{mmHg}$ in the sham group and for 24-h ambulatory $\mathrm{BP}$ were $7.0 / 4.4 \mathrm{mmHg}$ in the RDN and $3.1 / 3.0 \mathrm{mmHg}$ in the sham group. The mean baseline-adjusted difference (primary objective) in ambulatory BP (intention to treat population) between the RDN and the sham groups was $-4.6 /-4.3 \mathrm{mmHg}$ for $24-\mathrm{h}$ ambulatory BP $(P=0.0528 /$
$P=0.0028)$ in the Spyral HTN-OFF MED trial and -6.3/ $-2.6 \mathrm{mmHg}$ for daytime ambulatory BP $(P=0.0001 / 0.01)$ and $-4.1 /-1.8 \mathrm{mmHg}$ for $24-\mathrm{h}$ ambulatory BP $(P=0.006 /$ 0.07 ) in the Radiance-HTN SOLO trial (Fig. 1a and b). The Radiance-HTN SOLO study reported that the BP-lowering effect of RDN was consistent across age, sex, ethnicity, geography and baseline BP, and independent of the number of ablations. In the Spyral HTN-ON MED, 24-h ambulatory $\mathrm{BP}$ was reduced in the RDN group by -4.8 / $-4.3 \mathrm{mmHg}$ after 3 months and $-9.0 /-6.0 \mathrm{mmHg}$ after 6 months, compared with changes of $-0.2 /-0.6 \mathrm{mmHg}$ and $-1.6 /-1.9 \mathrm{mmHg}$ in the sham group, respectively. The mean difference in 24-h ambulatory BP in the Spyral HTN-ON MED (6 months FU) was $-7.0 /-4.3 \mathrm{mmHg}$ $(P=0.0059 / 0.0174)$.

Office BP: The mean baseline-adjusted differences in office BP between the RDN and the sham group were -6.5/ $-4.1 \mathrm{mmHg}(P=0.007 / 0.005)$, in Radiance-HTN Solo, $-7.1 /-5.0 \mathrm{mmHg}(P=0.0212 / 0.0076)$ in Spyral HTN-OFF MED and $-6.6 /-4.2 \mathrm{mmHg}(P=0.0250 / 0.0190)$ in the Spyral HTN-ON MED.

Even though these trials were not head-to-head comparative trials, the consistency of their BP and safety results vs. a sham procedure across various populations of hypertensive patients with various baseline BP and two different catheters allows to make the following statements: First, the primary objective measure, differences in ambulatory BP (daytime and 24-h) were quite similar between the three trials and between the techniques. Second, office BP reduction in the actively treated group (RDN group) was approximately $10 / 5 \mathrm{mmHg}$ decrease, irrespective of the trial. This includes the true RDN treatment and the sham effect, but from a patient perspective the overall achieved reduction in $\mathrm{BP}$ is the one that counts for the reduction in cardiovascular complications. Third, the sham subtracted reduction in ambulatory BP provides the clear message that RDN is effective in lowering BP in hypertensive patients without or with concomittant antihypertensive medication. Fourth, the biological proof that RDN is effective in humans and is now documented in three sham-controlled RCTs. Fifth, the pathophysiological contribution of the renal efferent and afferent nerves, mainly of sympathetic origin, in the maintenance of the BP level of patients with HTN is fully confirmed.

The similarity in the average BP decrease achieved in all these three trials using different methods and number of renal nerve ablations, suggests that first, there is a threshold number of ablations above which a plateau of the maximal effect is reached similarly to what is observed with antihypertensive drugs for which a flat dose response curve on BP is usually observed; second, the average decrease in BP which can be achieved with RDN in hypertensive patients is on average between 6 and $8 \mathrm{mmHg}$ in systolic ambulatory BP, indicating that the contribution of the renal sympathetic nervous system to the pathophysiological BP level in the hypertensive patients included in these trial is about this magnitude. Of note, there were individual patients with a much larger response to the procedure. Indeed, endovascular RDN only targets one of the many regulatory systems implicated in BP regulation. Significantly, this BP decrease is 
(a) 2 moLO

Daytime systolic BP

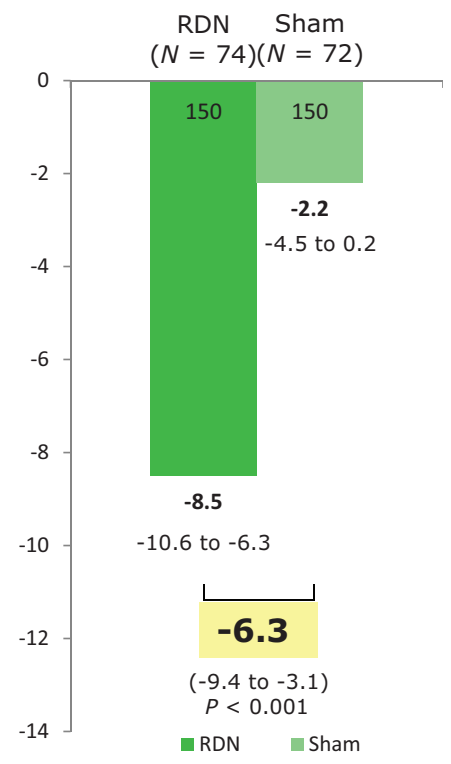

(b)

SOLO

2 months office systolic BP

RDN Sham

$(N=74)(N=72)$

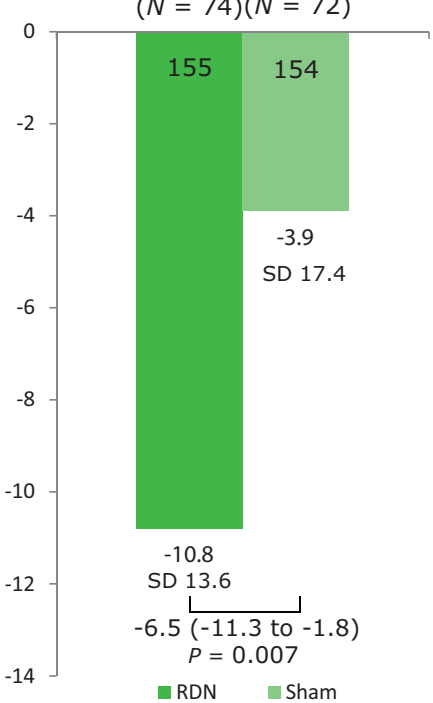

OFF Med

3 months

24-h systolic BP

RDN Sham

$(N=35)(N=36)$

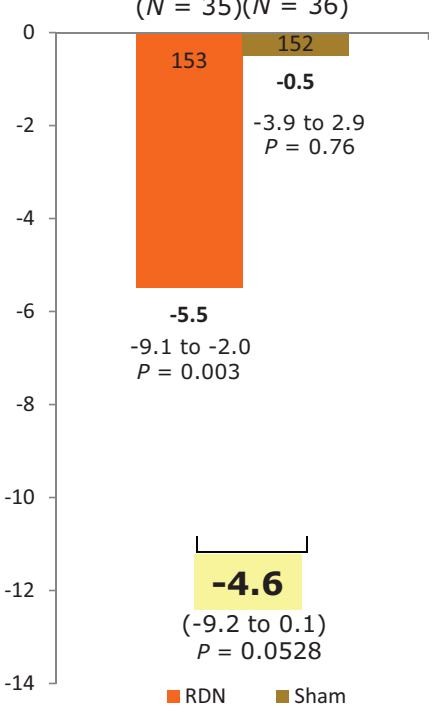

OFF Med

3 months office systolic BP

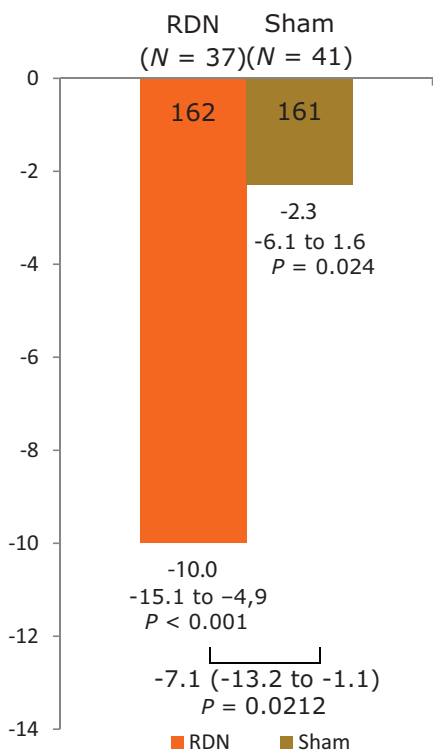

ON Med

6 months

24-h systolic BP

RDN Sham

$(N=36)(N=36)$

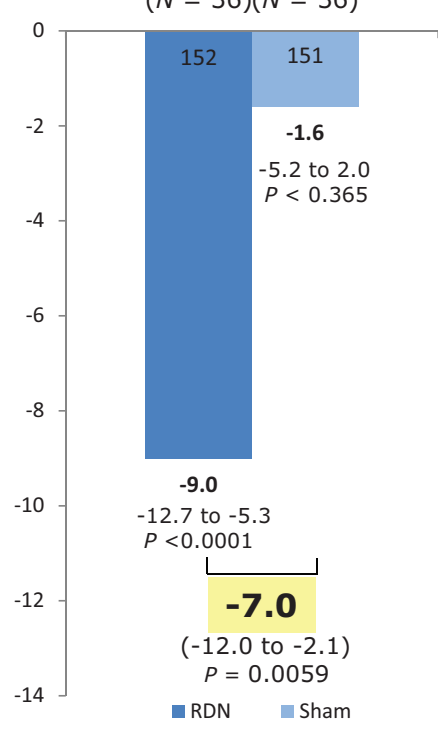

ON Med

6 months

office systolic BP

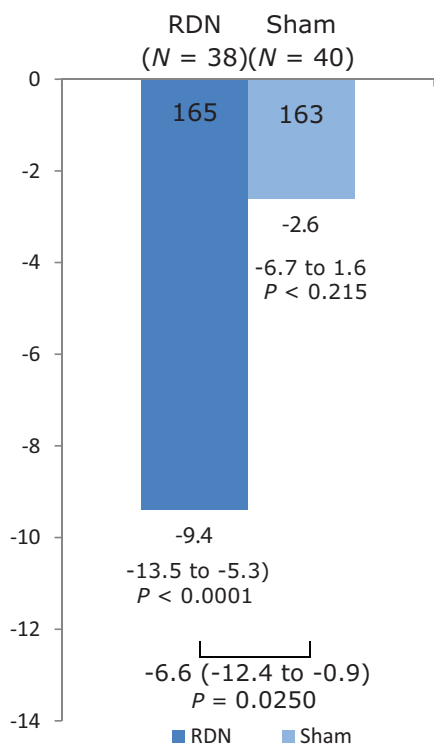

FIGURE 1 (a) Change in ambulatory blood pressure in RADIANCE SOLO, SPYRAL HTN OFF MED and SPYRAL HTN ON MED (baseline adjusted differences of blood pressure between the renal denervation and sham group are given). (b): Change in office blood pressure in RADIANCE SOLO, SPYRAL HTN OFF MED and SPYRAL HTN ON MED (baseline adjusted differences of blood pressure between the renal denervation and Sham group are given).

consistent with the average BP decrease reported with antihypertensive drugs targeting only one other system implicated in BP regulation, including RAS blockers, CCB, beta-blockers, diuretics etc. It should also be noted that the average BP decrease achieved with RDN (but also with antihypertensive drugs) masks the very large inter-individual variability in the $\mathrm{BP}$ response to any of these therapies to decrease BP. Laragh et al. [24] in his seminal article in HTN suggested that "individual response patterns to drugs reveal HTN mechanisms and may simplify treatment'. We can add now that that individual response patterns to renal denervation may also reveal HTN mechanisms in these individuals and thus simplify treatment for them. 


\section{Adherence to protocol and to treatment}

In the Radiance-HTN Solo trial, there was no drug-monitoring testing in serum or urine for assessing strict protocol adherence (i.e. patients should remain off antihypertensive medications throughout the 2-month follow-up). In the Spyral HTN-OFF MED trial over 90\% of the patients had no evidence of antihypertensive medication use at baseline as well as at 3 month follow-up assessed by drug monitoring. In contrast, medication adherence remained a major challenge in the Spyral HTN-ON Med trial. Indeed, 66\% of the patients in the RDN group and 60\% in the sham group only had full adherence to the ongoing antihypertensive treatment as assessed by drug monitoring, this proportion changed to 53 and 57\%, respectively, at 3 months and 62 and $64 \%$, respectively, at 6 months. In addition, nonprescribed antihypertensive medication was detected in 10$15 \%$ of the patient at each time point. Nevertheless, separate sensitivity analyses revealed that adherence was not a determinant of the BP response and thereby did not jeopardize the study results, a finding that has been also observed in the DENER-HTN trial $[3,4,25]$.

\section{Safety}

The safety profile of these two new catheters against a sham procedure was excellent. Beyond few femoral access hematoma not necessitating blood transfusions, no major adverse events occurred in the three trials in the short term from 30 days to 6 months postprocedure. There was no report of acute renal failure, renal artery dissection or perforation. eGFR remained stable throughout follow-up in the three studies. Longer follow-up with larger numbers of patients undergoing RDN will be necessary to provide evidence of safety and to exclude rare adverse events.

\section{Clinical relevance of the observed blood pressure reduction in sham-designed randomized trials of second generation}

So far, no prospective RCT has been published or is under way that analyzes the BP-lowering effect with bilateral RDN on cardiovascular, cerebrovascular and renal endpoints and total mortality. However, the clinical meaning of the observed BP reduction with RDN observed in the three sham-designed RCTs 2.0 can be estimated in the light of meta-analyses and RCTs that reported the cardiovascular benefit after BP reduction with oral antihypertensive medications. First, in the largest meta-analysis comprising 613815 patients from 123 studies, reduction of office BP by $10 \mathrm{mmHg}$ was associated with the reduction of cardiovascular events by $20 \%$, overall mortality by $13 \%$, coronary artery disease by $17 \%$, strokes by $27 \%$ and heart failure by 28\%, respectively [26]. Second, in a meta-analysis of 147 randomized trials comprising 464.000 patients a reduction in $10 \mathrm{mmHg}$ systolic and $5 \mathrm{mmHg}$ diastolic office BP was related to a decrease of coronary heart disease and stroke events by roughly 22 and 41\%, respectively, depending on the age of the patient [27]. Third, in the HOPE-3 study, patients with baseline office BP more than $143.5 \mathrm{mmHg}$ (mean $154 \mathrm{mmHg}$ ) had a reduction of BP by -5.8 / $-3.0 \mathrm{mmHg}$ (due to pharmacologic therapy) associated with a 28\% lower incidence of cardiovascular events compared with the placebo group [28]. In conclusion, although not definitely proven by a prospective outcome trial, we can expect that the 10-mmHg decrease in office BP achieved in RDN trials, if maintained long term, would be associated with a reduction in cardiovascular events by roughly 25\% (in particular with respect to heart failure and stroke).

On the other hand, we have to precisely evaluate the safety of RDN. So far, in the sham-controlled RCTs of first and second generation, no safety signal has emerged [2]. This is confirmed by the safety data from Symplicity HTN-3 with 340 interventions [17]; however, in this trial, ablation of branch arteries was not mandated. Nevertheless, safety concerns with respect to long-term safety issues (development of renal artery stenosis), consequences of RDN in clinical conditions in which high-sympathetic activity might be desirable [3,4,29] needs to be captured and balanced against the benefits of RDN.

\section{LIMITATIONS OF THE RANDOMIZED TRIALS OF SECOND GENERATION}

(1) The three trials were short-term studies, of which two were proof-of-concept studies as part of the SPYRAL program. Continued follow-up and additional studies will be important to evaluate the durability, safety and long-term clinical impact of RDN in patients with various forms of HTN.

(2) None of the trials used a physiologic test to confirm that successful and complete renal ablation was achieved. However, there is no simple and reproducible method available, at least currently to assess this procedural endpoint.

(3) There was a substantial heterogeneity of the BPlowering responses to RDN as well as to the sham procedure in the three trials.

Therefore, despite these promising new results which open widely again the field of RDN, we agree with the current recommendations of the European Guidelines 2018 that 'device based therapies are not recommended for routine use in the treatment of HTN at least at the current moment' [5]. However, we recommend to conduct RDN in the framework of 'clinical studies and sham-controlled RCT (to) further provide safety and efficacy in larger set of patients' [5]. So far the number of patients included in the trials is small, the follow-up duration short and several important questions remain unanswered.

\section{NOT YET ANSWERED QUESTIONS}

Question 1: Which technology has the best benefit/risk ratio in terms of $\mathrm{BP}$ lowering and cardiovascular events prevention? At the moment, RDN is performed with radiofrequency energy, ultrasound energy and by application of neurotoxic agents, such as alcohol. It remains uncertain whether energy delivery not only in the main arteries but also in the branches is necessary (as in HTN-ON-MED and HTN-OFF-MED) or circumferential ablation in the main artery is sufficient (as in Radiance-HTN Solo) [2-4]. The used technologies may also differ in the ability of nerve 
fibers to regenerate. So far, there is no clear evidence that any kind of nerve regeneration, although histologically observed, leads to physiological important effects. But observational follow-up duration is clearly limited.

Question 2: Another unsolved question is to identify those patients who respond most to RDN. Not surprisingly, in all studies, baseline BP has been identified as the major determinant of $\mathrm{BP}$ response, but this refers to the biological law that a high pretreatment value translates in a larger response [30]. More intriguing is the fact that patients with advanced arterial stiffness as indicated by aortic calcification [31], increased central and brachial pulse pressure or isolated systolic HTN showed an attenuated BP response after RDN $[32,33]$. This would exclude a majority of patients above 60 years that may suitable candidates for RDN. Other clinically important determinants of RDN have not yet been identified consistently through all studies. This underlines the necessity to identify biomarkers aiming to detect both the more RDN-responsive and sham-responsive patients prior the RDN. More treated patients are thus needed to understand which groups of patients might derive greater or lesser benefit.

Question 3: The target population for RDN may shift from severe resistant hypertensive patients (in whom RDN was the final treatment option) to patients with uncontrolled HTN (those without extensive cardiovascular or renal complications). In this case, this will require an intensive discussion with the patient, provision of unbiased information on potential benefits and risks and needs to take the patient's preference into account. In a survey of patients' perspective, it was found that $8.2 \%$ of responders would give up 2 years of their lives to avoid taking additional medications [34]. Likewise, in a patients' preference survey comprising more than 1000 patients in Germany, roughly $25 \%$ would opt for a single medical procedure, such as RDN, instead of taking more drugs. Thus patients' perspective emerges as an important determinant of treatment approaches in HTN in 2018 and beyond [35].

Question 4: Finally, as afferent and efferent renal nerves play also a crucial role in cardiovascular, metabolic and renal diseases beyond HTN, RDN may offer a new interventional treatment option for various conditions (congestive heart failure, atrial fibrillation, ventricular arrhythmias, chronic renal failure, obstructive sleep apnea, diabetes...). So far, the research activities in the field are characterized by proof of concept and pathogenetically orientated studies, but sham-designed RCTs are on the horizon.

No doubt, these positive results of the three sham RCT 2.0 will trigger the development of larger trials in HTN (sham-controlled RCTs 3.0), and open up the field for studies beyond HTN. We have interesting times ahead.

\section{ACKNOWLEDGEMENTS}

\section{Conflicts of interest}

R.E.S. received Speaker fees, Consultancy and Advisory Board fees from Ablative Solutions, Medtronic, Recor and ROX Medical. F.M. is supported by Deutsche Gesellschaft für Kardiologie, and Deutsche Forschungsgemeinschaft (SFB TRR 219), and has received grant support and personal fees from Medtronic and Recor. M.A. has received research grants from The French Ministry of Health, Servier, Novartis and Quantum genomics; has received honoraria for advisory board meetings from Actelion; and has received speakers' honoraria from CVRx, Servier and Astra. A.P. has received honoraria for advisory board or speaker's task from Ablative Solution, CVRx, Medtronic, Recor, Rox Medical, St Jude Medical. K.D. has received grant support from Medtronic, St Jude and Pythagoras. C.T. has received grant support and personal fees from Medtronic, Pythagoras and ST Jude. The other authors declare no conflicts of interests.

\section{REFERENGES}

1. Schmieder RE, Redon J, Grassi G, Kjeldsen SE, Mancia G, Narkiewicz K, et al. ESH position paper: renal denervation - an interventional therapy of resistant hypertension. J Hypertens 2012; 30:837-841.

2. Townsend RR, Mahfoud F, Kandzari DE, Kario K, Pocock S, Weber MA, et al. Catheter-based renal denervation in patients with uncontrolled hypertension in the absence of antihypertensive medications (SPYRAL HTN-OFF MED): a randomised, sham-controlled, proof-of-concept trial. Lancet 2017; 390:2160-2170.

3. Azizi M, Schmieder RE, Mahfoud F, Weber MA, Daemen J, Davies J, et al. Endovascular ultrasound renal denervation to treat hypertension (RADIANCE-HTN SOLO): a multicentre, international, single-blind, randomised, sham-controlled trial. Lancet 2018; 391:2335-2345.

4. Kandzari DE, Bohm M, Mahfoud F, Townsend RR, Weber MA, Pocock $\mathrm{S}$, et al., ISPYRAL HTN-ON MED Trial Investigators. Effect of renal denervation on blood pressure in the presence of antihypertensive drugs: 6-month efficacy and safety results from the SPYRAL HTN-ON MED proof-of-concept randomised trial. Lancet 2018; 391:2346-2355.

5. Williams B, Mancia G, Desormais I, Spiering W, Agabiti Rosei E, Azizi M, et al. 2018 ESC/ESH Guidelines for the management of arterial hypertension. J Hypertens 2018; (In press).

6. Schlaich MP. What we need to know about renal nerve ablation for treatment of hypertension and other states of sympathetic overactivity. Am J Physiol Renal Physiol 2016; 311:F1267-F1270.

7. DiBona GF, Kopp UC. Neural control of renal function. Physiol Rev 1997; 77:75-197.

8. Schiller AM, Pellegrino PR, Zucker IH. The renal nerves in chronic heart failure: efferent and afferent mechanisms. Front Physiol 2015; 6:224.

9. Grassi G, Seravalle G, Brambilla G, Trabattoni D, Cuspidi C, Corso R, et al. Blood pressure responses to renal denervation precede and are independent of the sympathetic and baroreflex effects. Hypertension 2015; 65:1209-1216.

10. Hering D, Lambert EA, Marusic P, Walton AS, Krum H, Lambert GW, et al. Substantial reduction in single sympathetic nerve firing after renal denervation in patients with resistant hypertension. Hypertension 2013; 61:457-464.

11. Esler M. Illusions of truths in the Symplicity HTN-3 trial: generic design strengths but neuroscience failings. J Am Soc Hypertens 2014; 8:593598.

12. Oparil S, Schmieder RE. New approaches in the treatment of hypertension. Circ Res 2015; 116:1074-1095.

13. Krum H, Schlaich M, Whitbourn R, Sobotka PA, Sadowski J, Bartus K, et al. Catheter-based renal sympathetic denervation for resistant hypertension: a multicentre safety and proof-of-principle cohort study. Lancet 2009; 373:1275-1281.

14. Esler MD, Krum H, Sobotka PA, Schlaich MP, Schmieder RE, Bohm M. Renal sympathetic denervation in patients with treatment-resistant hypertension (The Symplicity HTN-2 Trial): a randomised controlled trial. Lancet 2010; 376:1903-1909.

15. Azizi M, Sapoval M, Gosse P, Monge M, Bobrie G, Delsart P, et al. Optimum and stepped care standardised antihypertensive treatment with or without renal denervation for resistant hypertension (DENERHTN): a multicentre, open-label, randomised controlled trial. Lancet 2015; 385:1957-1965.

16. Esler MD, Bohm M, Sievert H, Rump CL, Schmieder RE, Krum H, et al. Catheter-based renal denervation for treatment of patients with treatment-resistant hypertension: 36 month results from the SYMPLICITY HTN-2 randomized clinical trial. Eur Heart J 2014; 35:1752-1759. 
17. Bhatt DL, Kandzari DE, O'Neill WW, D'Agostino R, Flack JM, Katzen $\mathrm{BT}$, et al. A controlled trial of renal denervation for resistant hypertension. N Engl J Med 2014; 370:1393-1401.

18. Kandzari DE, Bhatt DL, Brar S, Devireddy CM, Esler M, Fahy M, et al. Predictors of blood pressure response in the SYMPLICITY HTN-3 trial. Eur Heart J 2015; 36:219-227.

19. Fadl Elmula FE, Hoffmann P, Larstorp AC, Fossum E, Brekke M, Kjeldsen SE, et al. Adjusted drug treatment is superior to renal sympathetic denervation in patients with true treatment-resistant hypertension. Hypertension 2014; 63:991-999.

20. Rosa J, Widimsky P, Tousek P, Petrak O, Curila K, Waldauf $\mathrm{P}$, et al. Randomized comparison of renal denervation versus intensified pharmacotherapy including spironolactone in true-resistant hypertension: six-month results from the Prague-15 study. Hypertension 2015; 65:407-413.

21. Mathiassen ON, Vase H, Bech JN, Christensen KL, Buus NH, Schroeder $\mathrm{AP}$, et al. Renal denervation in treatment-resistant essential hypertension. A randomized, SHAM-controlled, double-blinded 24-h blood pressure-based trial. J Hypertens 2016; 34: 1639-1647.

22. Desch S, Okon T, Heinemann D, Kulle K, Rohnert K, Sonnabend M, et al. Randomized sham-controlled trial of renal sympathetic denervation in mild resistant hypertension. Hypertension 2015; 65:1202-1208.

23. Mahfoud F, Schmieder RE, Azizi M, Pathak A, Sievert H, Tsioufis C, et al. Proceedings from the 2nd European Clinical Consensus Conference for device-based therapies for hypertension: state of the art and considerations for the future. Eur Heart J 2017; 38:3272-3281.

24. Laragh JH, Lamport B, Sealey J, Alderman MH. Diagnosis ex juvantibus. Individual response patterns to drugs reveal hypertension mechanisms and simplify treatment. Hypertension 1988; 12:223-226.

25. Azizi M, Pereira H, Hamdidouche I, Gosse P, Monge M, Bobrie G, et al. Adherence to antihypertensive treatment and the blood pressurelowering effects of renal denervation in the renal denervation for hypertension (DENERHTN) trial. Circulation 2016; 134: $847-857$.
26. Ettehad D, Emdin CA, Kiran A, Anderson SG, Callender T, Emberson J, et al. Blood pressure lowering for prevention of cardiovascular disease and death: a systematic review and meta-analysis. Lancet 2016; 387:957-967.

27. Law MR, Morris JK, Wald NJ. Use of blood pressure lowering drugs in the prevention of cardiovascular disease: meta-analysis of 147 randomised trials in the context of expectations from prospective epidemiological studies. BMJ 2009; 338:b1665.

28. Yusuf S, Lonn E, Pais P, Bosch J, Lopez-Jaramillo P, Zhu J, et al. Bloodpressure and cholesterol lowering in persons without cardiovascular disease. N Engl J Med 2016; 374:2032-2043.

29. Singh RR, Sajeesh V, Booth LC, McArdle Z, May CN, Head GA, et al. Catheter-based renal denervation exacerbates blood pressure fall during hemorrhage. J Am Coll Cardiol 2017; 69:951-964.

30. Schmieder RE, Schmidt ST, Riemer T, Dechend R, Hagedorn I, Senges J, et al. Disproportional decrease in office blood pressure compared with 24-h ambulatory blood pressure with antihypertensive treatment: dependency on pretreatment blood pressure levels. Hypertension 2014; 64:1067-1072.

31. Courand PY, Pereira H, Del Giudice C, Gosse P, Monge M, Bobrie G, et al. Abdominal aortic calcifications influences the systemic and renal hemodynamic response to renal denervation in the DENERHTN (renal denervation for hypertension) trial. J Am Heart Assoc 2017; 6:; pii: e007065.

32. Mahfoud F, Bakris G, Bhatt DL, Esler M, Ewen S, Fahy M, et al. Reduced blood pressure-lowering effect of catheter-based renal denervation in patients with isolated systolic hypertension: data from SYMPLICITY HTN-3 and the Global SYMPLICITY Registry. Eur Heart J 2017; 38:93-100.

33. Ott C, Schmid A, Toennes SW, Ditting T, Veelken R, Uder M, Schmieder RE. Central pulse pressure predicts BP reduction after renal denervation in patients with treatment-resistant hypertension. EuroIntervention 2015; 11:110-116.

34. Hutchins R, Viera AJ, Sheridan SL, Pignone MP. Quantifying the utility of taking pills for cardiovascular prevention. Circ Cardiovasc Qual Outcomes 2015; 8:155-163.

35. Schmieder RE, et al. Patient preference for therapies in hypertension management. EuroPCR 2018; oral presentation. 